\title{
Interdecadal variation of Korea affecting TC activity in early 1980s
}

\author{
Jae-Won Choi, , Yumi Cha and Jeoung-Yun Kim
}

\begin{abstract}
By performing a statistical change-point analysis of activities of the tropical cyclones (TCs) that have affected Korea (K-TCS), it was found that there was a significant change between 1983 and 1984. During the period of 1984-2004 (P2), more TCs migrated toward the west, recurved in the southwest, and affected Korea, compared to the period of 1965-1983 (P1). These changes for P2 were related to the southwestward expansion of the subtropical western Pacific high (SWPH) and, simultaneously, elongation of its elliptical shape toward Korea. Because of these changes, the central pressure and lifetime of K-TC during P2 were deeper and longer, respectively, than figures for P1. This stronger K-TC intensity for $\mathrm{P} 2$ was related to the more southwestward genesis due to the southwestward expansion of the SWPH. The weaker vertical wind shear environment during P2 was more favorable for K-TC to maintain a strong intensity in the mid-latitudes of East Asia.
\end{abstract}

Keywords: Change-point analysis, Tropical cyclone, Korea, Shift, Vertical wind shear

\section{Background}

Many factors, including SST, vertical wind shear, thermodynamic instability/stability, upper-tropospheric momentum flux convergence, mid-tropospheric moisture, and so on have an influence on tropical cyclone (TC) activity (Gray 1968; Molinari and Vollaro 1989; Pfeffer and Challa 1992; DeMaria et al. 2001; Goldenberg et al. 2001; Baik and Paek 2001). In particular, TC movement and intensity in the subtropics or mid-latitudes are greatly influenced by environmental circulation systems, such as the location and strength of the subtropical western Pacific high (SWPH).

Chan and Shi (1996) fit the TC annual frequency in the Northwest Pacific into a second-order polynomial equation and observed that it has been increasing since 1994. Chu and Clark (1999) showed that the annual frequency of TCs was increasing in the central North Pacific. Kamahori et al. (2006) stressed that we must prepare against the effects of strong TCs because intense TC days have been increasing steadily for the last 30 years. Elsner et al. (2008) suggested similarly that the intensity

\footnotetext{
*Correspondence: choikiseon@daum.net

National Institute of Meteorological Sciences, 33, Seohobuk-ro, Seogwipo-si, Jeju 63568, South Korea
}

of strong TCs is increasing in all TC basins except the South Pacific Ocean basin, and that this increase was particularly evident in the North Atlantic and north Indian Ocean basins. Tu et al. (2009) showed that TC frequency over the Taiwan-East China Sea region has been increasing since 2000 because of northward shift of TC track over western North Pacific (WNP)-East Asian region. Landsea et al. (1996) claimed that the frequency of intense hurricanes in the Atlantic had been decreasing for the previous 50 years. Ho et al. (2004) proved through a statistical change-point analysis that the annual frequency of TCs in the East China Sea had been decreasing since the mid-1970s and that the decreasing trend was more distinct around the Philippines. As an extension of the study by Chan and Shi (1996) after analyzing TCfrequency data for the Northwest Pacific that had been updated through the early 2000s, Chan (2005) showed that the frequency of TCs had actually decreased since the mid-1990s. Chan also observed this decreasing trend in the annual frequency of TCs in the South China Sea over the prior 40 years.

Gong and Ho (2002) demonstrated that the SWPH has enlarged, intensified, and shifted southwestward in recent years, which gives rise to an anticyclonic circulation anomaly over the region from the South China 
Sea to the western Pacific, and thus causes wet anomalies over the Yangtze River valley. Ho et al. (2004) also showed that this southwestward expansion of the SWPH from the late 1970s leads to a decrease in TC passage frequency in the East China Sea, but to an increase in the South China Sea. In addition, they suggested that this change in the SWPH resulted in the westward shift of the recent major TC tracks and therefore contributed to a larger elliptic pathway of TC migration. On the contrary, Choi and Kim (2007) demonstrated that both frequency and intensity of a TC at landfall in the Korean Peninsula have rapidly increased since the late 1980s. In particular, they showed that the frequency of TC with intensity greater than tropical storm ( $34 \mathrm{kts} \leq$ maximum sustained wind speed $\leq 47 \mathrm{kts}$ ) has increased remarkably and suggested that this result is because a SWPH tend to retreat eastward in recent years.

On the other hand, in relation to the interdecadal variations in the climate of the summer climate, Inoue and Matsumoto (2007) showed that in the early 1980s, there were shifts not only in TC activity around Japan, but also in the entire large-scale circulation pattern over East Asia and the western North Pacific (WNP). Therefore, it was known that except for variation of Korean Peninsula landfalling TC, most of the climate changes associated with the activity of the SWPH in the aforementioned studies occurred between late 1970s and early 1980s. In fact, climate regime shift in the later 1970s or the early 1980s occurred not only in East Asia but also in the seas and air over the Pacific, and thus related various studies were accumulated (e.g., Nitta and Hu 1996; Niebauer 1998; Chang et al. 2000; Stephens et al. 2001; Bond et al. 2003; Wu et al. 2005; Ye and Hsieh 2006).

In the South China Sea and Western Pacific region, previous study also identifies a decadal shift of the TC activity in the early 1990s (Yang et al. 2012). Yang et al. (2012) has found that the South China Sea has more TCs during 1994-2008. They also attributed it to the eastward migration of SWPH, lower wind shear, higher midlevel humidity as well as warmer upper ocean conditions (sea surface temperature and upper ocean heat content). Another relevant study suggested that the wind shear, humidity, and vorticity related to monsoon variation and Indian Ocean Basin mode might be the cause of the change of TC activity over the western Pacific (Du et al. 2011). Xie et al. (2016) summarized the relationship of the East Asia Climate and climate modes in the tropical Indo-Pacific and proposed that the Indo-western Pacific ocean capacitor (IPOC) mode dominates the interannual and decadal climate over the region.

This study also found that a climate shift related to TC activity affecting Korea exists in the early 1980s. Thus, we first analyzed the interdecadal changes on the activity of the TC affecting Korea and then their relation to atmospheric circulation patterns in East Asia and the WNP regions.

\section{Data and methods}

The present study used the TC best track dataset archived by the Regional Specialized Meteorological Center (RSMC)-Tokyo (http://www.jma.go.jp/en/typh/). This dataset includes TC measurements at 6 -h intervals of latitude-longitude and intensity, including central pressure $(\mathrm{hPa})$ and maximum sustained wind speed (MSWS; kt). A TC that affected Korea (hereafter, K-TC) was defined as one that passed through the area of $32^{\circ}-40^{\circ} \mathrm{N}$, $120^{\circ}-138^{\circ} \mathrm{E}$ (Korea Meteorological Administration 1996; boxes in Fig. 2) for July-September. Based on this definition, 156 TCs were selected for the period of 1965-2004 (40 years). The reasons that the current study covered the period of 1965-2004 are as follows: Choi and Moon (2012) demonstrated that using K-TC frequency during summer (June-September), and significant regime shifts occurred in 2004, as well as in the mid-1960s and mid1980s. Choi and Kim (2007) showed that K-TC frequency had increased rapidly since the early-2000s and that the increase in the frequency of intense K-TC was more obvious. Their analysis showed that the reason for the increase was that the SWPH shifted to the east, resulting in the TC track moving to the east and reducing the frequency of TCs passing through mainland China before making landfall on the Korean Peninsula.

The TC intensity was divided into 5 stages on the basis of the intensity of the MSWS: tropical depression (TD; MSWS < 34 kts), tropical storm (TS; $34 \mathrm{kts} \leq \mathrm{MSWS} \leq 47 \mathrm{kts})$, severe tropical storm (STS; $48 \mathrm{kts} \leq \mathrm{MSWS} \leq 63 \mathrm{kts}$ ), typhoon (TY; MSWS $\geq 64 \mathrm{kts}$ ), and extratropical cyclone (EC). Storms at the TD and EC stages were included in the K-TC activity, because these storms cause tremendous damage in the mid-latitude countries of East Asia, such as China, Korea, and Japan (Kitabatake 2002).

On the other hand, we defined a K-TC recurving location as the point where a TC's direction of movement changes from a westward to an eastward movement. Also, to define the K-TC passage frequency, TC position was binned into the corresponding $5^{\circ} \times 5^{\circ}$ grid box and even if the same TC entered the same grid box multiple times, it was only counted once.

We also used the 6-h measurements of geopotential height (gpm), horizontal wind $\left(\mathrm{m} \mathrm{s}^{-1}\right)$, air temperature $\left({ }^{\circ} \mathrm{C}\right)$, and relative humidity $(\%)$ reanalyzed by the National Center for Environmental Prediction-the National Center for Atmospheric Research (NCEP-NCAR) to characterize the large-scale circulation patterns related to the decadal variation in the K-TC activity (Kalnay and 
Coauthors 1996; Kistler and Coauthors 2001). These data are available on a $2.5^{\circ} \times 2.5^{\circ}$ grid at standard pressure levels.

The NOAA Extended Reconstructed monthly Sea Surface Temperature (SST) (Reynolds et al. 2002), available from the same organization, was also used. The data have a horizontal resolution of $2.0^{\circ} \times 2.0^{\circ}$ latitude-longitude and are available for the period of 1854 to the present day.

Meanwhile, while TC data are accessible for the period from 1951 to the present, the reliability of TC data in the 1950 s and early 1960 s prior to the weather satellite era could lead to problems (Ho et al. 2005). The NCEPNCAR reanalysis data are also affected by two major changes in the observing system: upper air networks and satellite observations (Kistler and Coauthors 2001). To avoid any possible impact of unreliable data on the present results, all calculations are confined to the period from 1965 to 2004, during which weather satellites are used.

The interdecadal change in the K-TC activity was determined through a statistical change-point analysis (CPA). This type of statistical analysis can identify significant regime shifts in a time series in an objective manner. Because this variable does not follow a Poisson distribution, we use a different method to detect climate regime shifts in the temperature or passage frequency series: using a log-linear regression model in which a step function is expressed as an independent variable. If the estimated slope is at least twice as large as its standard error, one may reject the null hypothesis (i.e., the slope being zero) at the $5 \%$ significance level. The details of this analysis method are well described in Elsner et al. (2000) Chu (2002) and Ho et al. (2004) The vertical wind shear (VWS) analyzed to diagnose the large-scale condition related to the K-TC activity is calculated as follows:

$$
V W S=\sqrt{\left(u_{200}-u_{850}\right)^{2}+\left(v_{200}-v_{850}\right)^{2}} .
$$

Here, $u$ and $v$ indicate the zonal and meridional flows, respectively. 200 and 850 represent 200 and 850 -hPa levels, respectively.

The composite analysis is average for the months of the K-TC activity, and an anomalous map was obtained by subtracting the climatological summer (July, August, and September; JAS) mean during the period of 1965-2004 from the average for the months of K-TC activity. Here, JAS is defined as the seasons that the K-TC activity is the most active Park et al. (2006)

\section{Shift between 1983 and 1984} TC Frequency and recurving location

As a result of applying the K-TC frequency to the CPA, a significant change point was found between 1983 and
1984 (Fig. 1a). While there were $61 \mathrm{~K}-\mathrm{TCs}$ for the period of 1965-1983 (hereafter, P1), there were 95 for the period of 1984-2004 (hereafter, P2). That is, there were only about two-thirds as many K-TCs in P1 as in P2.

Ho et al. (2004) have already shown that the change in the TC passage frequency in the WNP is related to the southwestward shift of the SWPH in the late 1970s. Also, in the present study, an investigation was made of the change in the SWPH averaged for the months of the K-TC activity in each period, as shown in Fig. 2. As a result, the SWPH (5860 gpm contour) for P2 is shifted more southwestward than that for P1. At the same time, the shape of the SWPH becomes more elliptical toward Korea for P2. In addition, 5880 gpm contours for P2 were also stretched more toward Korea than those of P1 (not shown). This means that during P2, the SWPH provides a more favorable environment for TC to approach Korea. This feature can be confirmed in detail by examining the location of the SWPH for each K-TC during the two periods (right panel of Fig. 2).

Due to this southwestward expansion of the SWPH and its elliptical shape toward Korea, the K-TC track for P2
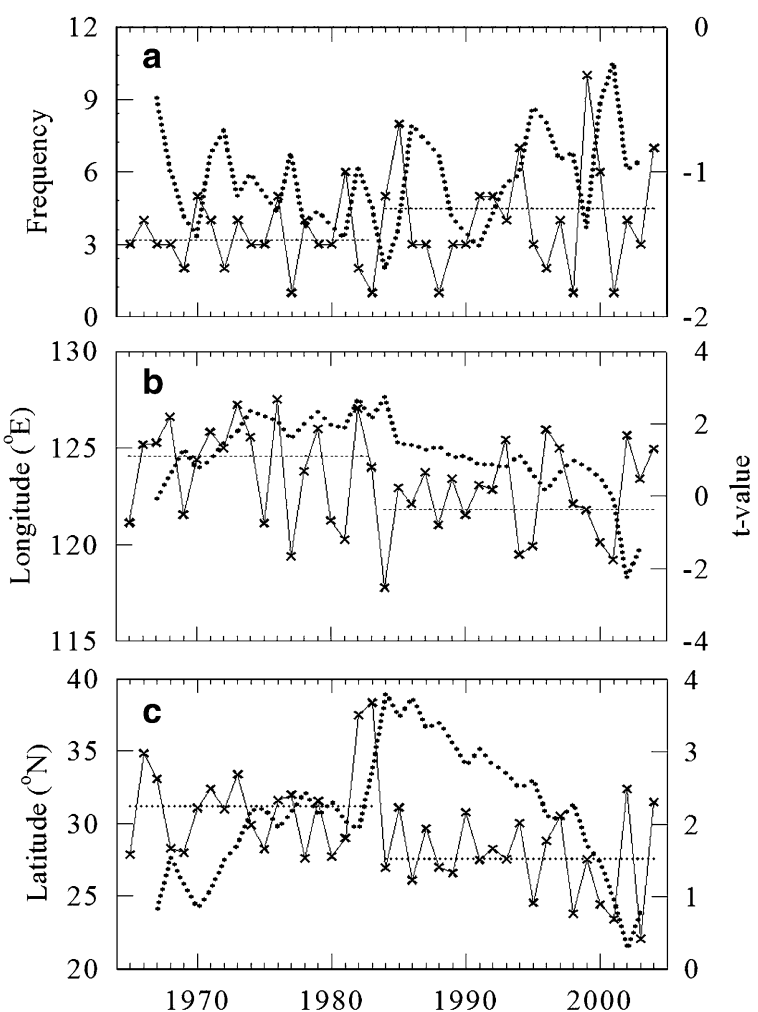

Fig. 1 Decadal variations in a frequency, $\mathbf{b}$ longitude, and $\mathbf{c}$ latitude for the recurving location of TCs affecting Korea (hereafter, K-TC). The thick and thin dotted lines denote t-values of change-point analysis and average values for three variables for the periods 1965-1983 (P1) and 1984-2004 (P2), respectively 

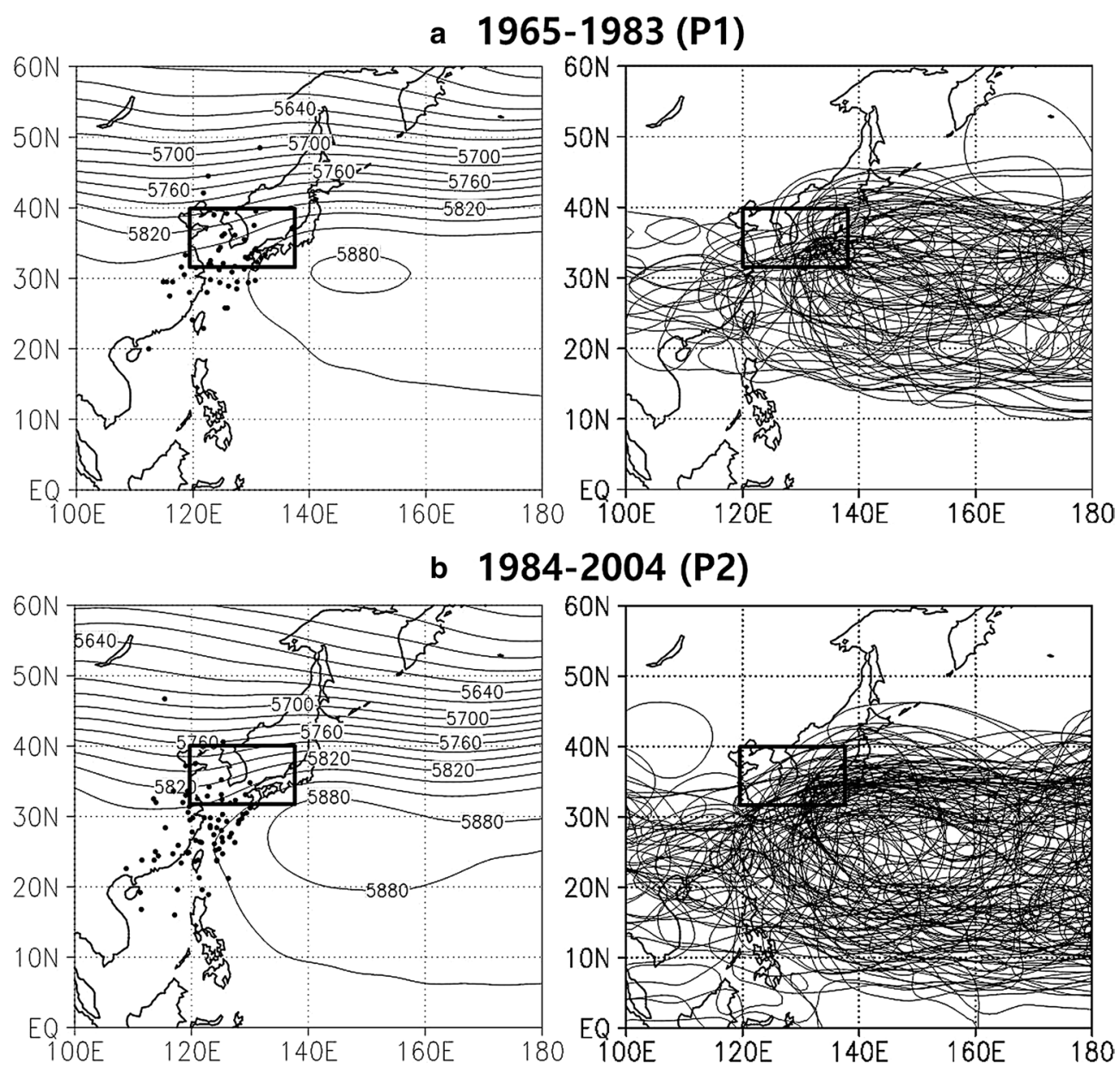

Fig. 2 500-hPa geopotential height composite averaged for the months of K-TC activity (left) and $5860 \mathrm{gpm}$ contours in each of the months with K-TC activity (right) for a P1 and $\mathbf{b}$ P2. The dots on the left denote the recurving locations of the K-TCs. The solid line box represents the K-TC area $\left(32^{\circ}-40^{\circ} \mathrm{N}, 120^{\circ}-138^{\circ} \mathrm{E}\right)$

tends to migrate more westward than that for P1 (Fig. 3). That is, the higher K-TC passage frequency for P2 is distributed along the western periphery of the $5860 \mathrm{gpm}$ contour (filled circle). Thus, East Asian coastal regions, such as the Philippines, the east coast of China, Korea, and Japan show a higher TC passage frequency for P2. This is well consistent with the results of Inoue and Matsumoto (2007) who analyzed the difference in the TC track frequencies in the late August between 1984 and 2000 and 1961-1983. On the other hand, the middle of China has the highest frequency in mainland China for P2. This may play an important role in the strengthening of wet anomalies over the Yangtze River valley in recent years, as analyzed by Gong and Ho (2002).

Generally, TCs tend to migrate along the western periphery of the SWPH. The recurving location of K-TCs may also change because of this recent shift in the SWPH. In relation to the change in the latitude of the recurving location, 34 of the 52 TCs $(65.4 \%)$ that recurved in P1 recurved to the north of $30^{\circ} \mathrm{N}$, while just 26 of the $77 \mathrm{TCs}$ (33.7\%) that recurved in P2 did so. In other words, about $70 \%$ of all the K-TCs that recurved during P2 recurved to the south of $30^{\circ} \mathrm{N}$. Therefore, it can be concluded that $\mathrm{K}-\mathrm{TCs}$ tended to recurve to the north of $30^{\circ} \mathrm{N}$ during $\mathrm{P} 1$ and to the south of $30^{\circ} \mathrm{N}$ during P2. On the other hand, in relation to the change in longitude, while only 7 of the 52 TCs for P1 recurved to the west of $120^{\circ} \mathrm{E}, 28$ of the $77 \mathrm{TCs}$ for P2 did so. Although the number of TCs that recurved to the west of $120^{\circ} \mathrm{E}$ is not very high for either period, the number of TCs that recurved to the west of $120^{\circ} \mathrm{E}$ for P2 is about four times that of P1. Also, in order to examine whether there was a significant change in the recurving location of K-TCs, we applied the time series of the latitude and longitude portions of the recurving locations to the CPA, respectively (Fig. 1b, c). Dramatically, this shows that there is clear change point between 1983 and 1984 for the two variables, just as with the TC frequency. The average recurving location for $\mathrm{P} 1$ is $31.2^{\circ} \mathrm{N}, 124.6^{\circ} \mathrm{E}$ and 


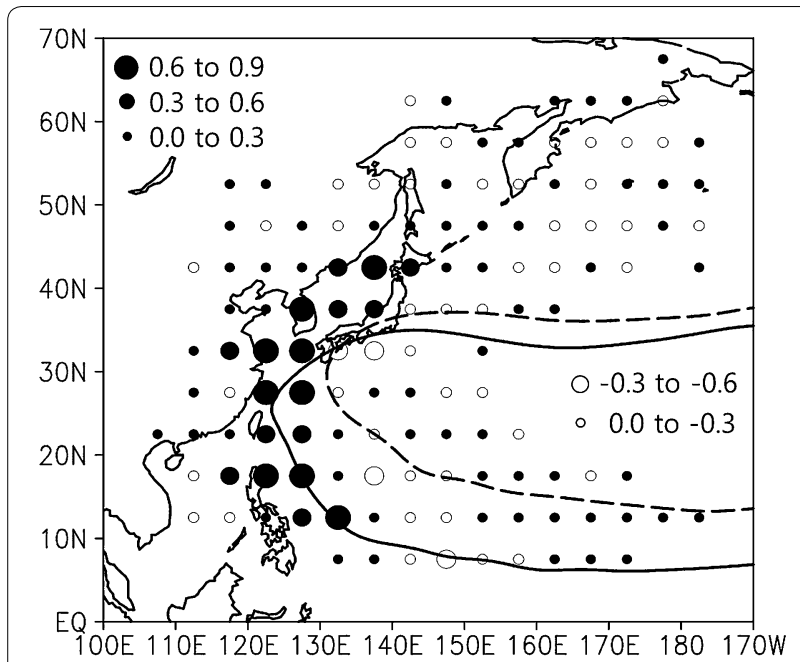

Fig. 3 Differences in mean K-TC passage frequencies (TPF) between $\mathrm{P} 2$ and $\mathrm{P} 1$ within each $5^{\circ} \times 5^{\circ}$ latitude-longitude grid box. The solid and dashed lines denote 5860 gpm contours for $\mathrm{P} 2$ and $\mathrm{P} 1$, respectively

it is $27.6^{\circ} \mathrm{N}, 121.8^{\circ} \mathrm{E}$ for P2. Therefore, we can objectively confirm through the CPA that the recurving location of K-TCs has been shifted more southwestward since 1984.

\section{TC intensity}

The shifts in the track and recurving location of K-TCs, along with the recent southwestward expansion of the SWPH, may have had an effect on TC intensity. Thus, the CPA was also applied to the interannual variation in the average central pressure in the maximal approach to the boundary line of the K-TC area using the 6-h TC best track dataset (Fig. 4). As a result, a significant shift was also shown between 1983 and 1984, like the frequency

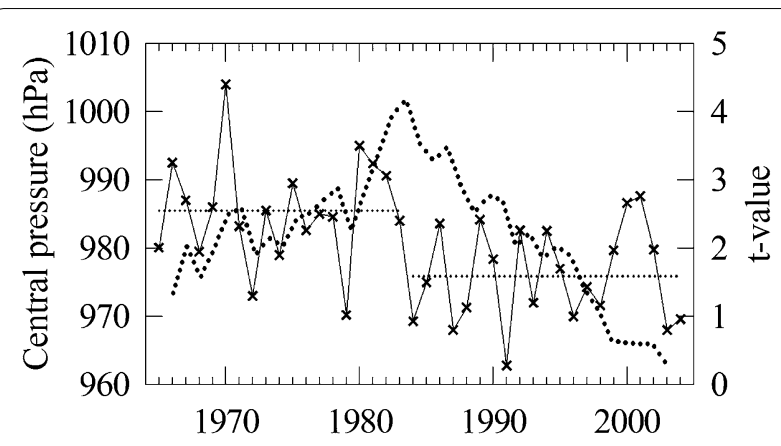

Fig. 4 As in Fig. 1, but for the annual variation in the central pressure averaged for the maximal approach to the boundary line of the K-TC area using the 6-h TC best track dataset

and recurving location shifts. That is, this means that all the activities related to a K-TC experienced a significant change between 1983 and 1984. The average central pressure $(975.9 \mathrm{hPa})$ for $\mathrm{P} 2$ is about $10 \mathrm{hPa}$ deeper than the average (985.5 hPa) for P1.

Wang and Chan (2002) pointed out that the further southeastward in the western Pacific a TC is when it is formed, the stronger its intensity becomes and, therefore, the longer its lifetime becomes. Accordingly, the latitudes and longitudes of K-TC genesis locations and the K-TC lifetimes for the two periods were analyzed, as shown in Fig. 5. In relation to the longitude, the TCs during P2 occur further to the east ( $\left.\mathrm{P} 1: 141.2^{\circ} \mathrm{E}, \mathrm{P} 2: 142.5^{\circ} \mathrm{E}\right)$, even though the difference between the two periods is not large. On the other hand, there is a difference of about $3^{\circ} \mathrm{N}$ for the latitude $\left(\mathrm{P} 1: 15.8^{\circ} \mathrm{N}, \mathrm{P} 2: 13.1^{\circ} \mathrm{N}\right)$. This more southeastward TC genesis for P2 may be related, not only to the monsoon trough, but also to the southwestward expansion of the SWPH Chen et al. (1998). In addition,

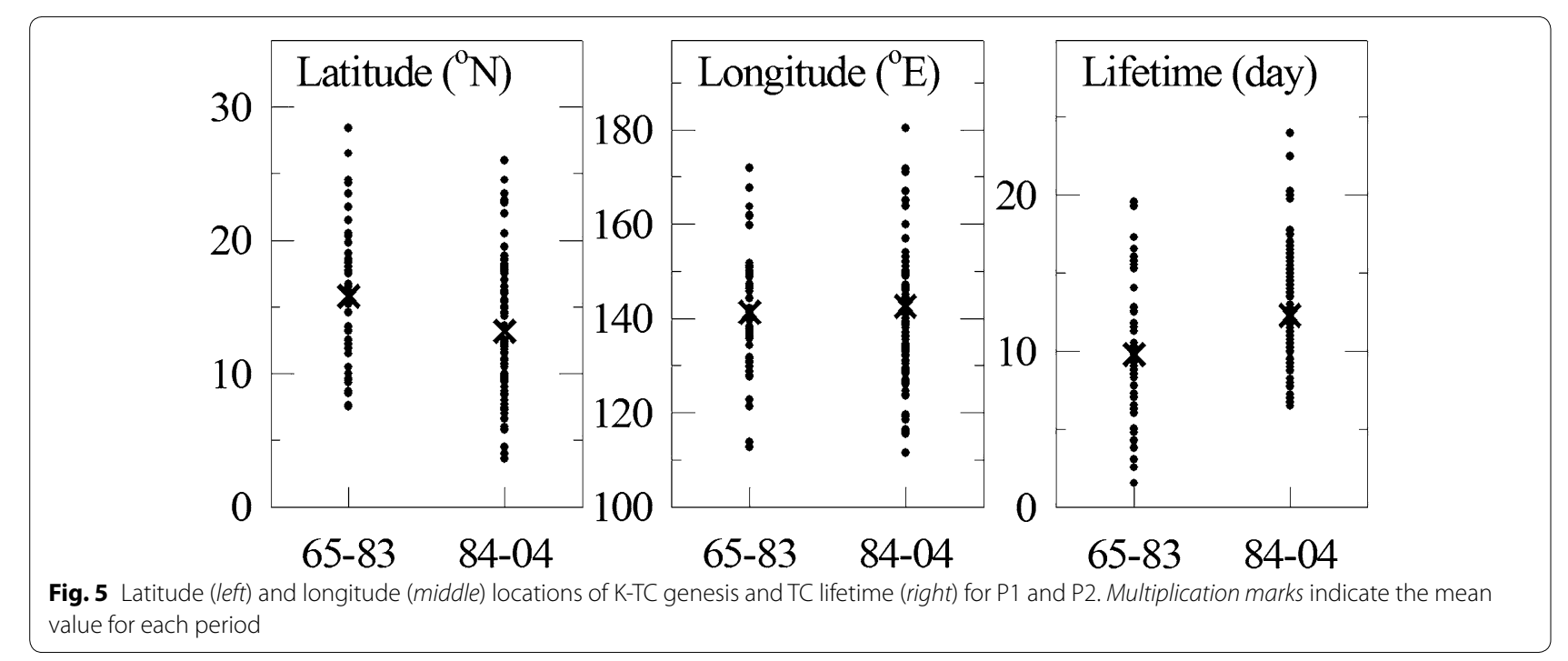


the closer to the equator a $\mathrm{TC}$ is during its formation, the longer its lifetime tends to become (P2:12.3 days, P1: 9.8 days), as indicated by Wang and Chan (2002).

\section{Vertical wind shear difference between P1 and P2}

In order to investigate the effect of large-scale conditions on the difference in the TC intensity between the two periods, we analyzed the vertical wind shear (VWS) anomalies for P1 (Fig. 6a) and P2 (Fig. 6b) and its difference between P2 and P1 (Fig. 6c). Associated with the VWS, Gray $(1968,1975)$ and McBride and Zehr (1981) have already emphasized that the patterns of the VWS have a critical role in an intensification of the

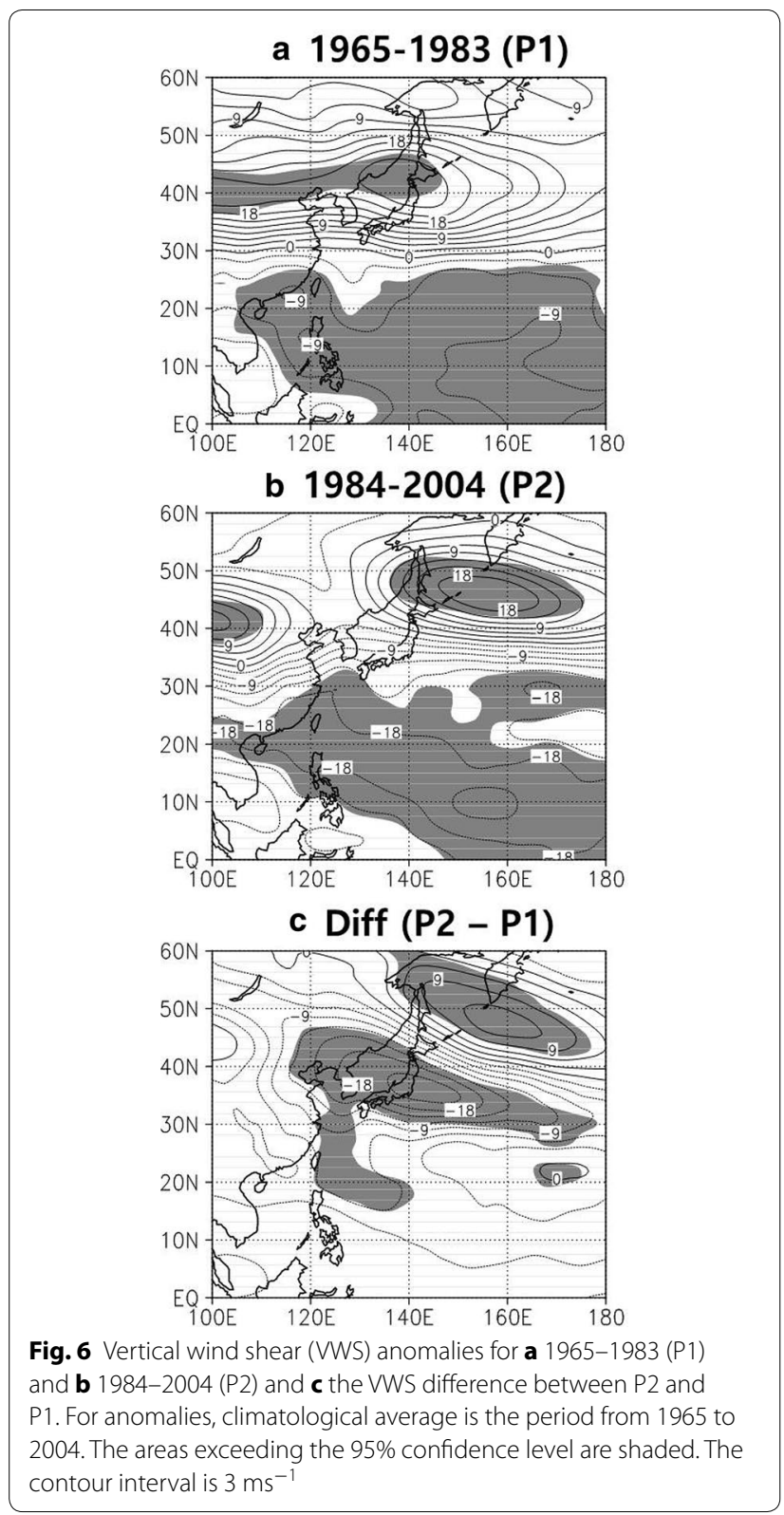

TC. While the center of the positive anomalies for P1 is located around Korea and Japan and the region of negative anomalies is located to the south of $30^{\circ} \mathrm{N}$ (Fig. 6a), the negative anomalies for $\mathrm{P} 2$ is located not only to the south of $30^{\circ} \mathrm{N}$, but also in Korea (Fig. 6b). In addition, the negative anomalies in the region south of $30^{\circ} \mathrm{N}$ for P1 are generally stronger for P2 (Fig. 6c). This indicates that during P2, K-TCs have a more favorable environment and thus could maintain stronger intensities than during $\mathrm{P} 1$, as analyzed in "TC intensity" section. In addition, in relation to the VWS difference between P2 and P1, the center of the negative anomalies is located in the mid-latitudes of East Asia, such as Korea, Japan, and some parts of northern China, and Japan. Also, most regions of the analysis area predominantly show negative anomalies. Consequently, this environment for P2 can also provide good conditions for maintaining a strong intensity in a K-TC, until it moves north into the mid-latitudes.

Eventually, it is concluded that the VWS in most regions of East Asia and the WNP is generally weaker for P2 than for P1. Thus, we can confirm that the period of $\mathrm{P} 2$ shows the potential for a TC to maintain a strong intensity in the mid-latitudes of East Asia.

After this study investigates other environmental fields, favorable conditions for TC intensification around Korea, such as anomalous warm sea surface temperature and warm air temperature, and anomalous high relative humidity are shown during P2 (not shown).

\section{Summary and conclusions}

The change-point analysis (CPA) was performed for tropical cyclone (TC) activities that affected Korea (K-TC) during the period of 1965-2004. As a result, we suggest that there is a clear shift in K-TC activities between 1983 and 1984 as follows: There were $95 \mathrm{TCs}$ for the period of 1984-2004 (P2) and only 61 for the period of 1965-1983 (P1). The tracks and recurving locations of these TCs shifted more westward and southwestward in P2, respectively. This recent shift in K-TC activities was related to the southwestward expansion of the subtropical western Pacific high (SWPH) and, simultaneously, its elliptic shape toward Korea.

Associated with the K-TC intensity, the central pressure of the TCs near Korea also showed a difference between the 2 years. That is, the average central pressure for P2 was about $10 \mathrm{hPa}$ deeper than that for P1. This was because the TCs during P2 occurred further to the southeast because of the recent southwestward expansion of the SWPH and, therefore, had a longer lifetime than those for P1. The cause of this difference in the TC intensity between the two periods was well confirmed through a vertical wind shear (VWS) analysis. The VWS for P2 was weaker over most regions of East Asia and the 
western North Pacific (WNP) than that for P1. Eventually, it could be determined that the period of P2 had a greater potential for a K-TC to maintain a strong intensity in the mid-latitudes of East Asia.

However, the increased typhoon activity that occurred in/around Korea starting in 1984 was not reflected basinwide (WNP). Yumoto and Matsuura (2001) and Matsuura et al. (2003) noted in common that the annual frequency of TCs in the WNP is high in the 1960s, low in the 1970s, and again high in the 1980s with a gradual increasing trend.

\section{Authors' contributions \\ JWC designed and carried out the study and wrote the paper. YC provided detailed information on East Asian meteorological data. JYK acquired and processed the data of YC. JWC, YC, and JYK contributed extensively to the scientific discussion. All authors read and approved the final manuscript.}

\section{Competing interests}

The authors declare that they have no competing interests.

\section{Funding}

This work was supported by the R\&D Project of the Korea Meteorological Administration "Development and application of technology for weather forecast."

Received: 26 October 2016 Accepted: 7 January 2017

Published online: 19 January 2017

\section{References}

Baik JJ, Paek JS (2001) Relationship between vertical wind shear and typhoon intensity change, and development of three predictor intensity prediction model. J Meteorol Soc Japan 79:695-700

Bond NA, Overland JE, Spillane M, Stabeno P (2003) Recent shifts in the state of the North Pacific. Geophys Res Lett. doi:10.1029/2003GL018597

Chan JCL (2005) Interannual and interdecadal variations of tropical cyclone activity over the western North Pacific. Meteorol Atmos Phys 89:143-152

Chan JCL, Shi JE (1996) Long-term trends and interannual variability in tropical cyclone activity over the western north Pacific. Geophys Res Lett 23:2765-2767

Chang CP, Zhang Y, LiT (2000) Interannual and interdecadal variations of the East Asian summer monsoon and tropical Pacific SSTs. Part II: the meridional structure of the monsoon. J Clim 13:4326-4340

Chen TC, Weng SP, Yamazaki N, Kiehne S (1998) Interannual variation in the tropical cyclone formation over the western North Pacific. Mon Weather Rev 126:1080-1090

Choi KS, Kim BJ (2007) Climatological characteristics of tropical cyclones making landfall over the Korean Peninsula. J Korean Meteo Soc 43:97-109

Choi KS, Moon IJ (2012) Changes in tropical cyclone activity that has affected Korea since 1999. Nat Hazards 62:971-989

Chu PS (2002) Large-scale circulation features associated with decadal variations of tropical cyclone activity over the central North Pacific. J Clim 15:2678-2689

Chu PS, Clark JD (1999) Decadal variations of tropical cyclone activity over the Central North Pacific. Bull Am Meteorol Soc 80:1875-1881

DeMaria M, Knaff JA, Connell BH (2001) A tropical cyclone genesis parameter for the tropical Atlantic. Weather Forecast 16:219-233

Du Y, Yang L, Xie SP (2011) Tropical Indian Ocean influence on Northwest Pacific tropical cyclones in summer following strong El Niño. J Clim 24:315-322

Elsner JB, Jagger T, Niu XF (2000) Changes in the rates of North Atlantic major hurricane activity during the 20th century. Geophys Res Lett 27:1743-1746

Elsner JB, Kossin JP, Jagger TH (2008) The increasing intensity of the strongest tropical cyclones. Nature 455:92-95
Goldenberg SB, Landsea CW, Mestas-Nunez AM, Gray WM (2001) The recent increase in Atlantic hurricane activity: causes and implications. Science 293:474-479

Gong DY, Ho CH (2002) Shift in the summer rainfall over the Yangtze River valley in the late 1970s. Geophys Res Lett 29(10):78-1-78-4. doi:10.1029/ 2001GL014523

Gray WM (1968) Global view of the origin of tropical disturbances and storms. Mon Weather Rev 96:669-700

Gray WM (1975) Tropical cyclone genesis. Atmospheric Sciences Paper No. 234. Colorado State University, Fort Collins

Ho CH, Baik JJ, Kim JH, Gong DY (2004) Interdecadal changes in summertime typhoon tracks. J Clim 17:1767-1776

Ho CH, Kim JH, Kim HS, Sui CH, Gong DY (2005) Possible influence of the Antarctic Oscillation on tropical cyclone activity in the western North Pacific. J Geophys Res 110:D19104. doi:10.1029/2005JD005766

Inoue T, Matsumoto J (2007) Abrupt climate changes observed in late August over central Japan between 1983 and 1984. J Clim 20:4957-4967

Kalnay E, Coauthors (1996) The NCEP/NCAR 40-year reanalysis project. Bull Am Meteorol Soc 77:437-471

Kamahori H, Yamazaki N, Maanji N, Takahashi K (2006) Variability in intense tropical cyclone days in the western North Pacific. Sola 2:104-107

Kistler R, Coauthors (2001) The NCEP-NCAR 50-year reanalysis: monthly means CD-ROM and documentation. Bull Am Meteorol Soc 82:247-267

Kitabatake N (2002) Extratropical transformation of typhoon Vicki (9807): structure change and the role of upper-tropospheric disturbances. J Meteorol Soc Japan 80:229-247

Korea Meteorological Administration (1996) Typhoon white book. Korea Meteorological Administration, Seoul

Landsea CW, Nicholls N, Gray WM, Avilia LA (1996) Downward trends in the frequency of intense Atlantic hurricanes during the past five decades. Geophys Res Lett 23:1697-1700

Matsuura T, Yumoto M, lizuka S (2003) A mechanism of interdecadal variability of tropical cyclone activity over the western North Pacific. Clim Dyn 21:105-117

McBride JL, Zehr R (1981) Observational analysis of tropical cyclone formation, Part II: comparison of non-developing versus developing systems. J Atmos Sci 38:1132-1151

Molinari J, Vollaro D (1989) External influences on hurricane intensity. Part I: outflow layer eddy angular momentum fluxes. J Atmos Sci 46:1093-1105

Niebauer HJ (1998) Variability in Bering Sea ice cover as affected by a regime shift in the North Pacific in the period 1947-1996. J Geophys Res 103:27717-27737

Nitta T, Hu ZZ (1996) Summer climate variability in China and its association with $500 \mathrm{hPa}$ height and tropical convection. J Meteorol Soc Japan 74:425-445

Park JK, Kim BS, Jung WS, Kim EB, Lee DG (2006) Change in statistical characteristics of typhoon affecting the Korean Peninsula. Atmosphere 16:1-17

Pfeffer RL, Challa M (1992) The role of environmental asymmetries in Atlantic hurricane formation. J Atmos Sci 49:1051-1059

Reynolds RW, Rayner NA, Smith TM, Stokes DC, Wang W (2002) An improved in situ and satellite SST analysis for climate. J Clim 15:1609-1625

Stephens CS, Levitus S, Antonov J, Boyer TP (2001) On the Pacific Ocean regime shift. Geophys Res Lett 28:3721-3724

Tu JY, Chou C, Chu PS (2009) The abrupt shift of typhoon activity in the vicinity of Taiwan and its association with Western North Pacific-East Asian climate change. J Clim 22:3617-3628

Wang B, Chan JCL (2002) How strong ENSO events affect tropical storm activity over the western North Pacific. J Clim 15:1643-1658

Wu L, Lee DE, Liu Z (2005) The 1976/1977 North Pacific climate regime shift: the role of subtropical ocean adjustment and coupled ocean-atmosphere feedback. J Clim 18:5125-5140

Xie SP, Kosaka Y, Du Y, Hu K, Chowdary JS (2016) Indo-western Pacific ocean capacitor and coherent climate anomalies in post-ENSO summer: a review. Adv Atmos Sci. doi:10.1007/s00376-015-5192-6

Yang L, Du Y, Xie S, Wang D (2012) An inter-decadal change of tropical cyclone activity in the South China Sea in early 1990s. Chin J Oceanol Limnol 30:138-144

Ye Z, Hsieh WW (2006) The influence of climate regime shift on ENSO. Clim Dyn 26:823-833

Yumoto M, Matsuura T (2001) Interdecadal variability of tropical cyclone activity in the western North Pacific. J Meteorol Soc Japan 79:23-35 